\title{
TRES ÁMBITOS PARA LA INTERVENCIÓN NORMATIVA URGENTE POR EL CONSEJO REAL DE CASTILLA: AUTOS Y ACUERDOS SOBRE UNIVERSIDAD, ABOGACÍA E IMPRENTA
}

\author{
Ignacio EZQUERRA REVILLA \\ Instituto Universitario "La Corte en Europa" (IULCE)
}

Recibido: 07/09/2012

Aceptado: 09/10/2012

\begin{abstract}
RESUMEN: Los autos y acuerdos se definen como disposiciones otorgadas por el Consejo en su doble condición de tribunal supremo y máximo órgano político-administrativo de Castilla. Constituían una suerte de intervención legislativa de urgencia en el espacio de continuidad cortesana, el próximo y el alejado del lugar más permanente de residencia real, ante conflictos o disfunciones no calculados previamente. Si vale el presentismo jurídico, eran un remedo de desarrollo reglamentario de disposiciones de mayor rango. En este trabajo me detengo en los relativos a tres importantes aspectos de la Castilla de los Austrias: Universidad, abogacía, e impresión de libros.
\end{abstract}

PALABRAS CLAVE: Consejo Real de Castilla; Autos y Acuerdos; Felipe II; Felipe III; Universidad; Abogacía; Imprenta.

ABSTRACT: The Autos and Acuerdos are defined as dispositions granted by the Consejo Real in his double capacity of Supreme Court and maximum political and administrative institution of Castile. They are a kind of urgent legislative intervention in the courtisan space, the nearest and the farest from the most permanent place of royal residence, in the face of conflicts or malfunctions not previously calculated. They are an imitative kind of actual regulative development of major range laws. In this work I stop in the Autos concerning to three important aspects of the Habsburg Castile: University, advocacy and printing books.

KEYWORDS: Consejo Real de Castilla; Autos y Acuerdos; Philip II; Philip III; University; Advocacy; Printing books.

Como ha señalado Bermejo Cabrero, "la figura jurídica del Auto acordado ha sido objeto de las más variadas interpretaciones en la literatura de ayer y de hoy"1. Los autos y acuerdos eran una forma legal y documental emanada de diferentes

1 Bermejo Cabrero, J. L. (2000). «Nueva Recopilación y Autos Acordados (1618-1745)», Anuario de Historia del Derecho Español, 70, pp. 37-88, p. 66. 
organismos cortesanos que, caracterizada por su intención ejecutiva, se aplicaba especialmente en el espacio local, aquel en que tenían una efectividad más inmediata. En lo que se refiere al Consejo Real, es difícil negar el carácter de auto a aquellas disposiciones del mismo dirigidas a otras instancias o poderes, ausentes en las recopilaciones legales conocidas. Pero, igualmente, por auto también se entendía una resolución jurisdiccional que sustanciaba cuestiones supletorias, no fundamentales, del procedimiento ${ }^{2}$. Es evidente que el Consejo Real de Castilla emitía esta clase de autos, pero esta interpretación no agota la versatilidad de un instrumento legal que expresaba la lenta construcción de un espacio gubernativo y administrativo, en igual medida que jurisdiccional, en la que han reparado distintos autores. Sin duda, la polisemia que lo afectaba venía ayudada por su clandestinidad inicial en el orden legislativo (cfr. al respecto nota 3), pero de la consideración conjunta de las definiciones coetáneas y los estudios actuales es posible proponer ciertos rasgos característicos.

\section{CARÁCTER Y DEFINICIÓN DE AUTO Y ACUERDO.}

Fernández de Mesa consideraba que, para ser llamado tal, el Auto debía ser aprobado en Consejo pleno, opinión avalada por el hecho de que muchos de ellos estaban rubricados por más de 10 miembros del Consejo ${ }^{3}$. Como quiera que no era usual la presencia de la totalidad de sus integrantes, es decir, Presidente y oidores tanto de planta como supernumerarios, entorpecida por la asistencia simultánea a Juntas, o la atención forzosa a la inercia de funcionamiento comisional propia del organismo, es obligado pensar que aquel número de rúbricas correspondía al Consejo Pleno. Éste solía reunirse los viernes por la mañana para completar mandatos derivados de la consulta de los viernes anterior con el rey (entre otros la formalización de autos aprobados, en su caso, por él) o posterior, a celebrar esa misma tarde. A este respecto, Fernández de Mesa afirmó, con términos propios de las Audiencias antes que del Consejo, que los autos eran aprobados "estando en acuerdo", si bien este requisito era compatible con la aprobación de otros autos

2 Gibert, R. (1984). «Los autos del Consejo de Castilla», en Boletín. Universidad Nacional de Educación a Distancia, Facultad de Derecho, pp. 109-116 [recurso electrónico] <http://espacio.uned.es/fez/eserv.php?pid=bibliuned:BFD-1984-11-12-30070\&dsID=PDF> [Consultado: 82011].

${ }^{3}$ Este detalle no se aprecia en las ediciones impresas de Autos y Acuerdos del Consejo, pero sí en los códices manuscritos en los que se iban asentando de forma cronológica, para su uso interno, a partir de los cuales se hicieron las primeras. Caso del conservado en la Biblioteca Nacional de España (en adelante BNE), ms 8667, que vengo estudiando.

${ }^{4}$ Arte histórica y legal, de conocer la fuerza, y uso de los Drechos (sic) Nacional, y Romano en España. Y de interpretar aquél por este, y por el propio origen... En Valencia: En la Imprenta de la 
por un número muy reducido de consejeros ${ }^{5}$. A su vez, los autos asentados en el manuscrito 8667 de la Biblioteca Nacional confirman una presunción ya formulada por Bermejo, y asociada a la puesta en marcha de la reforma del Consejo en 1608: la expedición de autos y acuerdos, además de por el Consejo Pleno, por la Sala de Gobierno, cuya indicción vino acompañada del inicio de un libro específicamente consagrado al asiento de tal clase de autos, el quinto de aquellos a los que remite la edición de los Autos de $1618^{6}$.

Pero el valor esencial de Fernández de Mesa fue atribuir a los autos y acuerdos un carácter político-administrativo y económico mostrado por su propio repertorio $^{7}$, que -como he señalado- en época contemporánea no valoró Gibert, pero sí otros autores como Pérez Prendes o Tomás y Valiente ${ }^{8}$. Con anterioridad, para Rafael Altamira la palabra auto "cubrió diferentes modalidades de resoluciones y órdenes, tanto judiciales como gubernativas" . Asimismo, al hablar del Consejo de Indias en su Análisis de la Recopilación de Indias afirmaba que "fue cuerpo administrativo a la vez que judicial en ciertas materias, y..., por tanto, será útil distinguir los autos de esas dos especies" ${ }^{\text {. }}$. Como quiera que la indicción de este Consejo, desgajado del Real, implicaba una concreción territorial de las atribuciones propias de este, se comprenderá fácilmente la presencia radical de ambas facetas en los autos y acuerdos promulgados por el Consejo Real, pese a que

Viuda de Gerónimo Conejos en frente de S. Martín, año 1747, p. 142. Por su parte, Rafael Altamira aplicó el término, en el contexto indiano, tanto a "la asamblea o reunión de los magistrados de audiencias, con o sin el virrey", como a las decisiones emanadas de aquella u otros órganos como el propio Consejo de Indias (ALTAMIRA y CREVEA, R. (1957). «Especies, formas y relación de las leyes en la legislación colonial española de las Indias Occidentales», [recurso electrónico] Revista de la Facultad de Derecho de México, 28, pp., 31-143, pp. 51-52 <www.juridicas.unam.mx/publica/librev/ rev/facdermx"cont/28/dtr/dtr2.pdf> (Consultado 09-2011).

5 Bermejo Cabrero, J. L. (2000) «Nueva Recopilación y Autos Acordados...», op. cit., p. 67.

${ }^{6}$ Autos y acuerdos del Consejo de que se halla memoria en los libros, desde el año de 1532, hasta el presente de 618. Mandados imprimir por el ilustríssimo señor don Fernando de Azevedo, Arçobispo de Burgos, Presidente del Consejo, y Señores dél. En Madrid. Por Luis Sánchez. Impressor del Rey N.S.. Año de M.DC.XVIII.

7 Al considerarlos "providencias económicas y generales del Consejo" (Arte histórica y legal..., p. 142)

${ }^{8}$ PÉrez Prendes, J.M. (1986). Curso de Historia del Derecho Español, Madrid: Universidad Complutense, p. 605; Tomás y VAliente, F. (1983). Manual de Historia del Derecho Español, Madrid: Tecnos, p. 378, autor que a su vez subraya la paulatina amplitud otorgada al término en el siglo XVIII (ambas obras apud BERMEJO CABRERO, J. L. (2000). Op. cit., p. 65).

${ }^{9}$ Altamira y Crevea, R. (1957). «Especies, formas y relación de las leyes...», op. cit., p. 97.

${ }^{10}$ Altamira y Crevea, R. (1941). Análisis de la Recopilación de las Leyes de Indias, de 1680, Buenos Aires: Instituto de Historia del Derecho Argentino, p. 266. 
hay especialistas que limitan a otro plano la efectividad de los autos y acuerdos ${ }^{11}$. Pero, de acuerdo con lo dicho, se definía una dualidad en la tipología del auto y acuerdo, conforme con su origen y ámbito de aplicación: por una parte, el administrativo o jurisdiccional (que predominará abrumadoramente en las compilaciones que manejo) $\mathrm{y}$, por otra, el procesal, determinado por el ritmo y orientación del procedimiento. En el primer sentido suponían, en opinión de María Isabel Cabrera, "reconocer al Consejo de Castilla cierta capacidad legislativa, y en virtud de una previa delegación real", en algunos de los casos ${ }^{12}$.

Para acercarse a la esencia del auto y acuerdo es muy útil la taxonomía legislativa planteada por Jordán de Asso y de Manuel en sus Instituciones del Derecho Civil de Castilla" ${ }^{13}$, quienes los consideraron el "Quarto estado de nuestra jurisprudencia", tras los concilios de época visigoda, los fueros locales y el ordenamiento real constituido por las Partidas, el Fuero Real y el Ordenamiento de Alcalá. Consideraban que ese estrato inferior estaba constituido junto con los Autos por las Pragmáticas, en cuya tramitación también se percibía la unicidad con la persona real que ambos autores atribuyen únicamente al Auto. Tales Pragmáticas resultaban, por una parte, "de las peticiones que el reyno hace en Cortes", 14 y, por otra, "... de las deliberaciones y decretos reales con que S. M. como supremo legislador del reyno, ocurre a las necesidades de él",15; como las contenidas en la recopilación de Las pramáticas del reyno publicadas en 1528, considerablemente aumentadas por Diego Pérez de Salamanca en 1546, y sin compilador continuo desde entonces, para disgusto de ambos autores ${ }^{16}$. Pero el caso es que en muchas

11 "En cuanto a los autos acordados, se trata de disposiciones que no rebasan el marco de la organización interna del Consejo o de los organismos directamente sometidos a su jurisdicción. En principio no estaremos ante disposiciones generales tocantes a la Corona de Castilla en las múltiples posibilidades de intervención del Consejo", Bermejo Cabrero, J. L. (2005). Poder político y administración en la España de los Austrias, Madrid: Ministerio de Justicia, p. 70.

12 Cabrera Bosch, M. I. (1993). El Consejo de Castilla y la ley, Madrid: CSIC, p. 213.

${ }^{13}$ Instituciones del Derecho Civil de Castilla por los Doctores D. Ignacio Jordán de Asso y del Río y D. Miguel de Manuel y Rodríguez..., Madrid. MDCCCV. En la Imprenta de la Real Compañía ( $6^{\mathrm{a}}$ ed.), pp. CI-CII.

14 Al modo de las contenidas, como indican ambos autores, en el Reportorio de todas las Premáticas, y capítulos de Cortes, hechos por Su Magestad, desde el año de mil y quinientos y veynte y tres, hasta el año de mil y quinientos y cincuenta y uno: hecho por el licenciado Andrés de Burgos... En Medina del Campo, en casa de Guillermo de Millis... 1551. [recurso electrónico] Repositorio Documental Gredos, Universidad de Salamanca <http://hdl.handle.net/10366/83118> [Consultado: 08-2011].

${ }^{15}$ Instituciones del Derecho Civil de Castilla, op. cit. p. CI.

16 Las pramáticas del Reyno: recopilación de algunas bulas del summo pontífice, concedidas en fauor de la jurisdicción real, con todas las pramáticas, y algunas leyes del reyno, hechas para la 
ocasiones el protagonismo e iniciativa en esas deliberaciones y decretos reales correspondía exclusivamente al Consejo Real, como se deduce de diferentes comunicaciones enviadas al rey ${ }^{17}$.

En esta línea -y sin reparar en su publicidad o no-, para estos autores el valor legal de los autos correspondía a la naturaleza común e indivisible del Consejo con el rey ${ }^{18}$, a su condición de receptáculo "de todo quanto toca a justicia y gobierno, que las leyes llaman mero y mixto imperio. De aquí se origina (continuaban) poder hacer este Consejo todo quanto el soberano puede por sí mismo, así en razón de promulgar leyes, como en todo lo demás"19. Pero consideraban que tales efectos legales los surtían sólo aquellos autos consultados previamente con el rey; condición que, implícitamente, parecen atribuir a la totalidad de los recopilados; cuando sólo era así en ocasiones, en virtud precisamente de esa identidad y confusión legal con el monarca ${ }^{20}$. Al margen de estas contradicciones, esta obra

buena gouernación y guarda dela justicia, y muchas pramáticas y leyes añadidas que hasta aquí no fueron impressas, en especial están añadidas las leyes de Madrid y de los Aranzeles y de los paños y lanas y capítulos de corregidores y leyes de Toro y leys de la hermandad..., En la villa de Alcalá de Henares: en casa de Miguel de Eguía..., 1528. Utilizo el asiento bibliográfico contenido en http://roai.mcu.es/es/registros/registro.cond?tiporegistro=MTD\&idBib=6792457

(Hispana) correspondiente a ejemplar del Repositorio Institucional de la Universidad de Granada, mútilo de portada.

${ }^{17}$ Por ejemplo: "Auiéndose entendido que en fraude de las leyes y pragmáticas que prohiuen el juego de dados bueltos y carteta se a yntroduçido los juegos que dizen del bolillo, tronpico, palo y otros en que ay encuentros, hazares y reparos como en los dados y que se juega en m[a]yor exceso que con ellos, a parecido ordenar la ley y pragmática que ua con esta para que siendo U. M[agesta]d seruido de firmarla se publique. De Madrid a XIIII de nouiembre de 1591 a[ñ]os", en Instituto Valencia de Don Juan (en adelante IVDJ). Envío 21, caja 31, n 379. En el sobrescrito se lee: "A Su M[ajesta]d. El Cons[ej]o Real 14 de noui[em]bre 1591. Con la prag[máti]ca q[ue] le pareçe se deue publicar para para (sic) prohibir el juego de bolillo, trompico y otros". Se lee una anotación complementaria, de difícil caligrafía y que no puede ser la respuesta real: "Ojo, $\mathrm{Al}$ amigo diré q[ue] juegue al tiempo".

${ }^{18}$ Sin importar la pérdida de competencias funcionales o geográficas que venía sufriendo desde el comienzo de la Edad Moderna: "Los autos, o cartas acordadas que pertenecen también al quarto estado de nuestra Legislación, tienen su origen en el establecimiento del supremo consejo de Castilla, que cuenta su antigüedad en el mismo nacimiento de esta corona. Aunque en tiempo de los señores reyes católicos se separaron de este supremo consejo algunos negocios propios y privativos, como son los de Guerra, Indias, y otros, a que obligó la extensión que estos reynos adquirieron por la conquista y herencia; y más adelante en el año de 1527 se desmembraron los negocios de estado, y finalmente los pleytos sobre los derechos del real patronato en el de 1603 en que se declaró a la Cámara por tribunal de justicia", Instituciones del Derecho Civil de Castilla, op. cit., p. CI.

${ }^{19}$ Instituciones del Derecho Civil de Castilla, op. cit., p. CII.

20 "Por tanto, a sus deliberaciones y acuerdos, que por la fundada presunción de que en este consejo residen siempre las personas más eminentes en sabiduría y experiencia, son hechos con toda 
indicaba nítidamente que, como mantengo, la importancia y efectividad de los autos y acuerdos dependía de -y manifestaba- la integración del Consejo con la persona real. Cosa distinta, y así lo insinuaba la referida creencia en la necesidad imprescriptible de consultar previamente al rey, era el alcance de esa efectividad legal genérica que cabe atribuir al auto, punto que ya tratara el mencionado Fernández de Mesa. A la vez que superaba el reduccionismo jurisdiccional en su interpretación, este atribuyó al auto la capacidad de declarar el Derecho, pero no derogarlo o contradecirlo, "porque esto sólo toca al mismo soberano"21. Aunque este era un punto controvertido a causa de la indicada condición del Consejo como materialización jurídica del rey, "cuyas resoluciones respetan hasta las leyes", este autor limitaba la efectividad legal general del cuerpo de autos y acuerdos del Consejo con argumentos tan sólidos como la discriminación efectuada en la Pragmática que autorizó la recopilación conjunta de leyes y autos en 1745, tan sólo dos años antes de que apareciese su obra ${ }^{22}$. Edición que legitimaba, para algunos autores, la consideración plena de los autos del Consejo como parte del Ordenamiento legal castellano.

De lo dicho, y de los temas que tocaron, cabe definir los autos y acuerdos como disposiciones otorgadas por el Consejo tanto en su calidad de tribunal supremo (preocupados por la forma y el fondo del ejercicio jurisdiccional) como de ente político-administrativo, cuyas resoluciones cubrían la totalidad del territorio

madurez y examen, se les da la fuerza y vigor de ley del reyno, para lo qual debe acompañar la indispensable consulta de S. M., único modo de reconocer y respetar la soberanía. Así, pues,, por razón de esta suprema jurisdicción, se entiende este primer tribunal del reyno, siempre que los despachos y demás cartas reales no expresan más que el consejo, los del mi Consejo, o de nuestro Consejo. Muchos de estos autos autos o acuerdos se hallan recopilados en la última impresión de la novísima Recopilación; pero como es tanto el número de otros que no se mencionan ni incorporan en este código, es digno de lamentarse el que vayan esparcidas, sin encontrarse una colección de ellas, la qual debía renovarse, o bien aumentarse con apéndices o adiciones de algunos, en algunos años". La necesidad de la consulta previa del auto con el rey era también mantenida en el Compendio del Derecho Público y Común de España, o de las Leyes de las Siete Partidas, colocado en orden natural, por el Lic. D. Vicente Vizcaíno Pérez,..., Tomo I. Madrid, MDCCXXXIV por D. Joachin Ibarra, Impresor de Cámara de S.M., p. XCII: "El Supremo Consejo de Castilla, en quien residen la inmediata jurisdicción de todo cuanto toca a justicia y gobierno, puede promulgar leyes, consultándolas antes con S. M. por cuyo medio representa y reconoce la real soberanía. A esta casta de leyes llamamos autos acordados" (asimismo transcrito en BERMEJO CABRERo, J. L. (2000). Op. cit., p. 66).

${ }^{21}$ Arte Histórica y Legal, de conocer la fuerza, y uso de los Derechos, op. cit., p. 142.

22 "Ni obsta a todo esto, el que los autos acordados son parte del cuerpo de la Recopilación, la qual está aprobada con autoridad regia; porque la pragmática que autorizó esta colección, aprobó cada cosa en su género, y por esso van en tomo aparte los autos separados de las Leyes" (Arte Histórica y Legal, de conocer la fuerza, y uso de los Drechos, op. cit., p. 143). 
castellano. Significaban una intervención legislativa apremiante en el espacio de continuidad cortesana, no sólo el más inmediato a la residencia más continua del rey, sino también el más alejado del mismo, ante circunstancias o eventualidades puestas de manifiesto en el ejercicio administrativo cotidiano. Por esta vía se concretaba o mejoraba la aplicación de las competencias propias del Consejo, o se reparaban las omisiones o defectos revelados por la legislación superior. Su vocación era excepcional, y suponían una suerte de desarrollo reglamentario de aspectos relevantes para la convivencia social o el interés regio, como podían ser aquellos de los que me ocupo en estas notas: la regulación normativa de la Universidad, el ejercicio de la abogacía en la Corte o la impresión de libros.

\section{RÉGIMEN UNIVERSITARIO.}

La supervisión de la normativa universitaria estaba explícitamente atribuida en las Ordenanzas del Consejo de 1608 a su Sala de Gobierno, si bien en términos excesivamente genéricos y con la llamativa contradicción de no conocer de las visitas de inspección de las que eran objeto, aunque sí de las conclusiones pertinentes que cupiera sacar de ellas para un mejor funcionamiento de las Universidades $^{23}$. En ejercicio de tales competencias, un auto de 17 de febrero de 1610 ordenó que el presidente de la Mesta visitase alternativamente, en sus dos años de mandato, las universidades de Salamanca y Valladolid, y otro oidor del Consejo la de Alcalá, disposición que demostraba la aleatoriedad que la mecánica comisional imponía en el funcionamiento del Consejo ${ }^{24}$.

Posteriormente, ante la queja de la Universidad de Salamanca, un auto del Consejo en Madrid, a 20 de noviembre de 1617, regulaba la forma de proveer sus cátedras, ante “... las desórdenes y excessos grandes que passan, assí de parte de pretendientes, como de estudiantes...”. Las de Cánones y Leyes serían votadas promiscuamente por todos los canonistas y legistas con tan sólo un curso de estudios; las de Teología, mediante voto obligatorio de todos los oyentes, tanto religiosos como seglares; las de Medicina, por médicos, teólogos y bachilleres en Artes; y, respecto a estas últimas, votarían aquellos que pudiesen hacerlo para

23 Por un lado, se indicaba, como competencia de la Sala “... el buen gobierno de las universidades", y se añadía poco más adelante: "De las visitas de tribunales y universidades y residençias, que se tomaren a corregidores y juezes ordinarios que se havrán de ver en las otras salas, suele resultar ser neçesario proveher algunas cosas tocantes al buen gobierno, que ofreciéndose combendrá se de quenta a esta sala para que la rebean, pues en ella prinçipalmente es mi voluntad se traten y consulten conmigo", DIOS, S. DE (1986). Fuentes para el estudio del Consejo Real de Castilla. Salamanca: Diputación Provincial, pp. 123-124.

${ }^{24}$ Autos y acuerdos del Consejo de que se halla memoria en los libros, desde el año de 1532, hasta el presente de 618, op. cit., auto 154. 
proveer las de Teología y las de Medicina ${ }^{25}$. Como se aprecia, el criterio de provisión no era lo suficientemente restrictivo, y ello propició que los problemas continuasen. A juzgar por la atención que la Sala de Gobierno continuó prodigando hacia la materia, este auto apenas tuvo efecto y una Provisión Real de 16 de febrero de 1621 comunicó a la Universidad la derogación de ciertos estatutos tocantes a la provisión de Cátedras y dispensó, en favor del maestro Cornejo, agustino y catedrático de Filosofía Moral, la necesidad de que los catedráticos de menores se opusieran a las cátedras vacantes de mayores. Lo importante de esta Provisión, a nuestros efectos, es que se fundaba en auto del Consejo -que transcribía- suscrito el día anterior, hecho que daba así, implícitamente, un rango legislativo superior al auto sobre la provisión ${ }^{26}$. En segundo lugar, e igualmente importante, el hecho de que el auto transcrito no conste entre los compilados en las ediciones impresas, confirma la presunción de que fueron muchos más los autos y acuerdos aprobados que los insertos en su recopilación; que, especialmente conforme fue acentuándose la complejidad del ejercicio gubernativo, debió comenzar a formarse con un criterio de generalidad o extensión de su alcance ${ }^{27}$.

La materia de la provisión de cátedras en la Universidad de Salamanca continuó siendo muy controvertida y la forma que tuvo el Consejo para atacar el problema, mediante su Sala de Gobierno, fue nuevamente la aprobación de un auto, el 19 de mayo de 1623, que reservaba al Consejo la provisión de las cátedras en las universidades de Salamanca, Valladolid y Alcalá y la detraía a los estudiantes, ante el poco resultado del "cuidado que el Consejo avía puesto en el remedio diversas vezes, y por diferentes caminos,....28. Nuevamente, el vehículo de la decisión fue

25 Op. cit., auto 190.

${ }^{26}$ Que, a su vez, se puede deducir de la capacidad del auto para modificar una Provisión Real previa, como se advierte en el de 12 de marzo de 1616 (Autos y acuerdos del Consejo de que se halla memoria en los libros,..., auto 182), que derogaba Provisión anterior que permitía que los oidores del Consejo que ejerciesen como presidentes de la Mesta llevasen la tercia parte de las condenas hechas en los pleitos por denuncia de reventa de hierbas. Otra Provisión Real, de 15 de febrero de 1621, permitió sin embargo a los alcaldes entregadores llevar la tercia parte en las causas de rompimiento de pastos comunes, ejidos y abrevaderos, de la que hasta entonces gozaban sólo en el caso de cañadas y dehesas auténticas, Quaderno de leyes, y privilegios del honrado concejo de la Mesta, con índice, y concordantes de Leyes Reales, Autos Acordados, y Capítulos de Millones. Colocado de orden de el Real y Supremo Consejo de Su Magestad: por el licenciado don Andrés Díez Navarro,... En Madrid, año de MDCCXXXI, p. 290.

${ }^{27}$ Como confirmación de lo que digo, cfr. la transcripción de la mencionada provisión en el apéndice documental de RodrígueZ-SAn PEDro BEZARES, L. (1986). La Universidad Salmantina del Barroco, periodo 1598-1625, III, Salamanca: Ediciones Universidad de Salamanca, pp. 745-747, muy buena prueba material de señalado carácter selectivo - no declarado- de la compilación de autos. 
Provisión Real, dada en Madrid el 26 de mayo de 1623, que, si bien en esta ocasión no incluyó el auto, presentaba un evidente parentesco estilístico con él ${ }^{29}$. Este era resultado de Consulta de los Viernes con el rey en la que el ponente fue el licenciado Garci Pérez de Araciel, cuyo ejercicio previo como fiscal real en el Consejo le había puesto en repetido contacto con cuestiones universitarias ${ }^{30}$.

\section{REGULACIÓN DEL EJERCICIO DE LA ABOGACÍA EN LA CORTE.}

El sentido del auto o acuerdo como precisión, complemento o refuerzo de disposiciones legislativas de mayor calado se advierte asimismo en aquellos que se ocuparon del ejercicio de su profesión por los abogados de la Corte. Conocida la estrecha relación entre ellos y el mundo oficial (patente en la presencia de muchos miembros del Consejo Real entre los tempranos integrantes de la Congregación de Abogados de la Corte, fundada en 1596 previa aprobación del propio Consejo ${ }^{31}$ ),

${ }^{28}$ Autos y acuerdos del Consejo de que se halla memoria en los libros,..., op. cit., auto 222.

${ }^{29}$ Igualmente transcrita en RodríGUEZ-SAN PEDro BEZARES, L. (1986). Op. cit., pp. 757-758. Así la cláusula del auto "con grandes ofensas de N. Señor, y perjuyzio del bien público, que tanto interessa en la buena educación de la juventud", queda convertida en la provisión: "con grande ofensa de Nuestro Señor y perjuycio del bien público y enseñanza de la jubentud que en esa Unibersidad se cría".

${ }^{30}$ Como se deduce de Provisión Real de 20 de septiembre de 1618, sobre irregularidades de graduación en ciertas universidades, y Cédula Real de 5 de febrero de 1621, en confirmación de la pompa en los grados. Ambos documentos son transcritos en Rodríguez-SAN PEdro BezARES, L. (1986). Op. cit., pp. 908-909 y 913-915.

${ }^{31}$ La creación de la Congregación de Abogados necesitaba remover un añejo obstáculo, la suspicacia regia hacia las congregaciones gremiales, que la Pragmática de 25 de mayo de 1552 prohibía explícitamente (Ley IV, título XIV, libro octavo de la Recopilación), a consecuencia de su compromiso con las Comunidades. Aunque otro era el contexto, la referida fundación sólo se podía hacer con elevados contactos consiliares, como los que relacionaban al doctor Ascensio López y el presidente Rodrigo Vázquez de Arce, ZuluetA, J. A. De (1980). El Doctor Ascensio López: fundador del Colegio de Abogados de Madrid y Letrado de la Villa, Madrid: Ilustre Colegio de Abogados, pp. 16 y 124. En Barbadillo Delgado, P. (1956). Historia del Ilustre Colegio de Abogados de Madrid, I, Madrid: s.n., pp. 166-171, se contiene una relación de miembros de los Consejos que irían formando parte de la Congregación desde 1595: Melchor de Molina, Alonso Pérez de Ágreda, Juan de Ocón y Trillo, Rodrigo Vázquez de Arce, Pedro Díez de Tudanca, Alonso de Anaya Pereira, Núñez de Bohórquez, Diego Fernando de Alarcón, Pedro de Tapia, Francisco de Contreras, Gil Remírez de Arellano, etc., etc. La condición de la profesión de abogado como cantera para abastecer los Consejos fue asimismo subrayada en la Idea de un abogado perfecto, reducida a práctica, deducida de reglas y disposiciones del Derecho, comprobada con la autoridad de sus intérpretes... que ofrece, dedica y consagra... el licenciado don Melchor de Cabrera Núñez de Guzmán, abogado de los Consejos..., En Madrid, en la oficina de Eugenio Rodríguez y a su costa. Año de 1683 (ed. facsímil especial del IV centenario del Ilustre Colegio de Abogados de Madrid, 1996), esp. pp. 66-67. El proceso de creación de la Congregación, entre la primera reunión fundacional de 15 de agosto de 1595 y la aprobación de sus Ordenanzas el 15 de julio de 1596, también es tratado en PérEZ 
sorprende el contenido del auto de 5 de febrero de $1594^{32}$. Limitaba la extensión de las escrituras de los abogados y, con ello, sus derechos, imponiéndoles realizarlas breve y compendiosamente, en latín y "sin romance alguno". Pero el auto se inscribía en toda una tradición legal, como la representada por la ley XXIX, tít. XVI, libro Segundo de la Recopilación, de 1554, que ordenaba a los abogados limitarse a cobrar a las partes su salario y la justa retribución del escribiente. Tras la Pragmática de 13 de junio de 1590, centrada en las incompatibidades del ejercicio de la abogacía por razón de parentesco, que prohibía los pactos entre abogados y procuradores "para llevar parte alguna del estipendio o ynterese que los tales abogados llevaren...", las denominadas Ordenanzas de abogados de 1595 trataron, en la línea del auto mencionado, de la retribución de los abogados de Consejo y audiencias, al insistir en lo que no dejaba de ser un concepto aleatorio: “... se contenten de llevar honestos y templados salarios por su trabajo de los pleytos en que ayudaren". Si bien fijaban el límite de la cantidad por percibir en la vigésima parte del valor total del pleito, sin superar en ningún caso los 30.000 mrs. ${ }^{33}$. Otro auto de 12 de octubre de 1611 volvió sobre el régimen de actuación de los abogados y les obligaba a acudir cotidianamente al Consejo, poco antes del inicio de sus sesiones y durante toda la jornada, y a hablar con brevedad, conforme a la ley de Partida $^{34}$.

No sé si la repetición coordinada y enlazada de Pragmáticas y Autos que asoma en este caso cabe en alguno de los tipos de ley definidos, con grandes dosis de humor, por Luciano Vandelli: ciclotímica, autista, egoista, esquizofrénica, obsesiva, placebo, anoréxica, présbita, neurótica, etc ${ }^{35}$. Quizá responda a una mezcla de obsesión, neurósis y esquizofrenia motivada por la repetida inobservancia de lo legislado, con bastantes gotas de desorientación. Pero, en

Bustamante, R. (1996). El Ilustre Colegio de Abogados de Madrid, 1596-1996, Madrid: Ilustre Colegio de Abogados de Madrid, pp. 126-130. Y, sobre todo, por SuÁrez BILBAO, F. (2005). Génesis de una institución colegial. La Congregación y Colegio de Abogados de la Corte de Madrid (15961732), Madrid: Dykinson.

${ }^{32}$ Autos y acuerdos del Consejo de que se halla memoria en los libros,... , op. cit., auto 228.

33 Pérez Bustamante, R. (1996). Op. cit., pp. 121-126, con transcripción de la Pragmática de 1590, “... para que ningún abogado lo pueda ser en las causas que se trataren en el Consejo y otros tribunales en que padre o hijo o yerno o cuñado fuere juez y tratándose ante un juez sólo no pueda abogar padre, hijo, yerno y cuñado del tal juez ny puedan haçer conciertos los abogados y procuradores sobre llevar parte del ynterese".

${ }^{34}$ Con lo que se deduce que los autos poseían un valor aclaratorio sobre el conjunto de la legislación vigente, al margen del momento de promulgación de la disposición de la que se tratase, Autos y acuerdos del Consejo de que se halla memoria en los libros, ..., op. cit., auto 157.

${ }^{35}$ VAndeLli, L. (2007). Trastornos de las instituciones políticas, Madrid: Editorial TrottaFundación Alfonso Martín Escudero, con un «Prólogo para españoles» de Francisco SoSA WAGNER. 
cualquier caso, creo que tal repetición representa un ejemplo, mitigado en el tiempo, de afecciones tan características de la actividad legislativa, en un sentido intemporal, como la hipertrofia -casi la hiperémesis- y la ineficacia. Digo lo anterior porque el 20 de febrero de 1617 fue promulgada, con un indiscutible aire de familia con el primero de los autos mencionado -y primero de los contenidos en el referido manuscrito de la Nacional-, una detallada Premática por la qual se manda, y da orden del número de hojas, que han de tener las informaciones en derecho, y cómo se ha de tassar el premio, y precio, que los abogados han de llevar por ellas a las partes, y las penas, que se han de executar en los abogados, que excedieren de lo contenido en esta premática, y que ninguno lo pueda ser, sin ser primero examinado, y aprovado, conforme a las leyes deste reyno ${ }^{36}$. El valor aclaratorio e incidental característico del auto tuvo ocasión de mostrarse repetidamente a partir de ese momento, con la publicación de tres en pocos meses, vinculados a la referida Pragmática madre. El primero data de 11 de julio de ese año, que reiteraba el cumplimiento de lo contenido en ella respecto a la indicación y firma por los abogados, de los derechos y otros premios recibidos por hacer informaciones en Derecho. Lo que, en rigor, parecía contradecir la doctrina previa, ya aludida, que impedía cobrar a los abogados por realizar tales informaciones, y asemejaba al conjunto de Pragmáticas y Autos sobre el asunto con lo que Vandelli denominaría ley stop and go. A su vez, este auto presentaba un fuerte contraste con el ya referido de 5 de febrero de 1594, y es que, si entonces la notificación del auto por Juan de Cendejas era detallada nombre a nombre, en este caso era sustituida con una diligencia genérica de Hernando de Vallejo: "Queda en mi poder el auto orijinal y las notificaciones que se hicieron a los letrados" 37 . El incremento en el ritmo anual de aprobación de autos era sólo una expresión más de un proceso expansivo en el volumen de producción documental del Consejo, y ello propició que los escribanos de Cámara economizasen su tarea.

\footnotetext{
${ }^{36}$ Fue publicada en Madrid, por Juan de la Cuesta, en 1617. Su licencia de impresión, expedida el 9 de noviembre de 1617, fue reservada, como era común al escribano de Cámara más antiguo del Consejo ( $c f r$. al respecto los"Discursos generales y particulares..." de Moriana en Dios, S. DE (1986). Fuentes para el estudio del Consejo Real de Castilla, p. 278) en este caso Hernando de Vallejo, GIL Ayuso, F. (2001). Noticia bibliográfica de textos y disposiciones legales de los reinos de Castilla impresos en los siglos XVI y XVII, Junta de Castilla y León (ed. facsímil de la de Madrid, 1935), pp. 184-185. La sucesión de Pragmáticas contenidas en esta obra, y el cese súbito de Juan Gallo de Andrada como beneficiario de las licencias dos días antes de la señalada fecha (en la Premática, para que se pueda tirar a la caça con arcabuz, o con escopeta, o con otro tiro de pólvora, o con vala..."), induce a pensar que este dejó por entonces de ser el escribano de Cámara de mayor antigüedad.

37 BNE. Ms. 8.667, f. 58r.; Autos y acuerdos del Consejo de que se halla memoria en los libros, ..., op. cit., auto 187.
} 
Un segundo auto, de 10 de noviembre de 1617, matizaba que otro aspecto fundamental de la Pragmática, la obligatoriedad del examen, debía ser entendida para aquellos que pretendiesen comenzar a ejercer con posterioridad a su promulgación. Y que este examen tendría lugar en la Sala de Gobierno, al tiempo que se establecía la obligación de juramento ante el Consejo tanto para quienes ejerciesen antes de esa fecha, como para quienes pretendiesen hacerlo a partir de ella $^{38}$. El tercer auto, de 23 de noviembre del mismo año, aclaraba todavía los anteriores, al advertir que la exención de examen por razón de ejercicio previo de la abogacía se entendía sólo con aquellos ejercientes en la Corte de forma continua con antelación de dos años a la fecha de promulgación de la Pragmática. Añadía además que, examinados o no, los abogados de la Corte no ejercerían hasta recibir licencia por el Consejo, lo que implícitamente, daba a este flexibilidad en lo relativo a aquellos que no estaban obligados a pasar un examen. A su vez, se concedían ocho días como plazo para inscribirse en la referida Congregación, una vez recibida la preceptiva licencia ${ }^{39}$.

\section{AUTOS SOBRE IMPRESIÓN DE LIBROS.}

Otro terreno en el que el auto sirvió para redondear legislación superior, cuya aplicación había aconsejado mayor detalle o precisión, fue el de la impresión de libros. Como es sabido, de ella se ocupó -al margen de la mención a la expedición de licencias de impresión por parte del Consejo, contenida en las Ordenanzas de $1554^{40}$-, la Pragmática de 7 de septiembre de $1558^{41}$ que encarnó un acabado intento de dar forma administrativa a unos requisitos de control de origen doctrinal. En primer lugar, la Pragmática prohibía introducir en Castilla cualquier obra prohibida por el Santo Oficio, y ordenaba quemar aquellas que ya lo estuvieren e imprimir el Índice de libros prohibidos, y distribuirlo entre libreros y mercaderes ${ }^{42}$.

38 Autos y acuerdos del Consejo de que se halla memoria en los libros, ..., op. cit., auto 189.

${ }^{39}$ Autos y acuerdos del Consejo de que se halla memoria en los libros, ..., op. cit., auto 192.

40 Dios, S. DE (1986). Fuentes para el estudio del Consejo Real de Castilla, p. 103: "Item mandamos que de aquí adelante las licencias que se dieren para ymprimir de nuevo algunos libros de qualquier condición que sean, se den por el presidente, e los del nuestro Consejo, e no en otras partes. A los quales encargamos los vean y examinen con todo cuydado antes que se den las dichas licencias, por que somos informados, que de averse dado con facilidad se han impresso libros inútiles y sin provecho alguno, a donde se hallan cosas impertinentes. Y bien ansí mandamos que en las obras de importancia quando se diere la dicha licencia, el original se ponga en el dicho Consejo, por que ninguna cosa se pueda añadir o alterar en la impressión".

${ }^{41}$ Utilizo la transcripción de REYES, F. DE (2000). El libro en España y América: legislación y censura (siglos XV-XVIII), Madrid: ARCO/Libros, pp. 799-804.

${ }^{42}$ REYES, F. DE (2000). El libro en España y América..., op. cit., pp. 800-801. 
De acuerdo con la letra de la disposición, en adelante ningún libro sería impreso en Castilla sin ser presentado previamente en el Consejo, al efecto de que una o más personas especialmente comisionadas diesen su aprobación. Sólo concedida esta el organismo otorgaría su licencia, "firmada de nuestro nombre y señalada de los del nuestro Consejo". Pero, al margen de su concreción formal, la Pragmática era importante, entre otros detalles, porque por su medio el Consejo retenía la aplicación directa de una disposición legislativa emanada de sí mismo, hecho poco habitual. Dado que en la mayoría de las ocasiones la supervisión y cumplimiento de sus propias provisiones requería forzosamente de la intervención de oficiales subordinados o autoridades territoriales, caso de los corregidores. Es otro índice de la importancia que se concedía a la materia, de índole, como he indicado, doctrinal e ideológica; aunque es cierto que en esta Pragmática, el corregidor quedaba convertido en brazo auxiliar de la jerarquía eclesiástica en la intercepción de libros procedentes del exterior de Castilla.

Así, apuntaba ya una preocupación confirmada con el propio uso de la Pragmática, que requirió un instrumento legislativo más concreto, la Pragmática y declaración sobre los libros ecclesiásticos que vienen impressos fuera del reyno. $Y$ para que de aquí adelante en estos reynos no se pueden (sic) imprimir sin licencia de los señores del Consejo de Su Magestad ",43, de 27 de marzo de 1569. En ella, se ordenaba a los corregidores velar por la no introducción de misales o breviarios impresos fuera de Castilla, o que no hubieran recibido la preceptiva licencia del Consejo $^{44}$. Entre ambas pragmáticas, el auto ya había mostrado su virtud para enunciar puntos apenas esbozados en otra legislación. El publicado el 9 de noviembre de 1565 trataba sobre "... los derechos que ha de llevar el corretor de los libros, que sea a respeto de lo inpresso, i no del original" ${ }^{\text {". }}$. A su vez, otro auto, de 7 de agosto de 1594, obligó a los escribanos de Cámara a especificar en las certificaciones de tasas de libros, la de cada uno de los pliegos, y la suma de todos ellos ${ }^{46}$.

La aplicación de este conjunto legislativo mostró, con el paso del tiempo, sus imperfecciones, respecto a la intención con que fueron promulgadas sus distintas partes, en manera especial desde la promulgación en 1610 de la Pragmática para

${ }^{43}$ Una copia impresa, en IVDJ, e. 21, c. 31, no 230. Cit. además en GIL AyUso, F. (2001). bibliográfica de textos y disposiciones legales de los reinos de Castilla ..., op. cit., pp. 77-78.

${ }^{44}$ Punto subrayado por GonZÁLEZ Alonso, B. (1982). El corregidor castellano (1348-1808), Madrid:, pp. 224-225.

${ }^{45}$ Autos y acuerdos del Consejo de que se halla memoria en los libros, ..., op. cit., auto 44.

${ }^{46}$ Autos y acuerdos del Consejo de que se halla memoria en los libros, ..., op. cit., auto 138. 
que no se puedan imprimir fuera destos reynos las obras y libros que en ellos compusieren, o escrivieren, de qualquier facultad que sean ${ }^{47}$. Por ella, se prohibía a los súbditos del rey "llevar, ni embiar a imprimir, ni imprimir en otros reynos las obras y libros que conpusiere o escriviere de nuevo...". Desde su misma aplicación, mostró la debilidad propia de las disposiciones que regulaban un no acto, en vez de un $a c t o$, y dio lugar a una casuística perjudicial tanto para los creadores, como para los impresores. Para estos, la persecución de una práctica, la impresión en el extranjero, que buscaba evitar los trámites propios de la Pragmática de 1558, podía estar justificada por interés particular. Pero, por el camino, eran muchos los perjuicios causados a los libros de autores castellanos residentes en otros reinos, o fallecidos y de privilegio extinguido, o aquellos que requerían de un arte de imprenta inexistente en Castilla por rareza de los tipos, u otras características. $\mathrm{O}$ a la industria editorial de los otros reinos peninsulares ${ }^{48}$. La inmediata picaresca surgida para orillar la nueva norma llevó al Consejo a intervenir. En uso de sus funciones tutoras de la legalidad, el fiscal, el licenciado Diego de Corral y Arellano, planteó ante el Consejo los fraudes que se hacían en la impresión y entrada de libros, tanto por naturales como por extranjeros. Y nuevamente fue el auto el medio arbitrado para intentar desterrarlos. El organismo promulgó auto, el 15 de septiembre de 1617, que ordenaba aplicar la legislación vigente, esto es, las Pragmáticas de 1558 y 1569, a las primeras impresiones de autores extranjeros, y a las segundas de autores naturales, pero impresas en reinos distintos de Castilla. Al tiempo que se prohibía explícitamente la impresión en otros reinos de primeras ediciones de autor natural castellano. Para garantizar la atención de los escribanos de Cámara del Consejo ante solicitudes que pudieran vulnerar este punto, se les prohibía recibirlas y, si por inadvertencia se les daba curso y terminaban recibiendo licencia, las obras serían incautadas, y el infractor multado con $50.000 \mathrm{mrs}^{49}$.

Un aspecto destacable de este auto es que encarecía la aplicación del conjunto legislativo en materia de imprenta al oidor del Consejo encargado de supervisar la introducción de obras en Castilla. Era uno de los muchos terrenos que demostraban la naturaleza comisional del trabajo desarrolado en el seno del Consejo, y disponemos de pruebas de cómo obedeció este mandato el oidor entonces

${ }^{47}$ En Madrid. Por Juan de la Cuesta. Véndese en casa de Francisco de Robles, Librero el Rey nuestro Señor. 1610, pub. por ReYes GómEZ, F. DE Los (2000). El libro en España y América..., op. cit., II, 837-839.

${ }^{48} \mathrm{Al}$ respecto se extiende ReYes Gómez, F. DE Los (2000). El libro en España y América..., op. cit., I, pp. 274-282.

49 Autos y acuerdos del Consejo de que se halla memoria en los libros, desde el año de 1532, hasta el presente de 618, op. cit., auto 188. 
responsable, el licenciado Pedro de Tapia. Lo hizo mediante otro auto particular, de 19 de octubre de 1617, por él personalmente suscrito, en el que se insistía en el contenido del previamente publicado y se ordenaba a los libreros de la Corte y el conjunto de los reinos de Castilla la exposición del mismo en parte visible de sus tiendas. Toda una demostración de una práctica que ganará impulso en el siglo XVII, ante el creciente volumen de la documentación administrativa, la notificación de órdenes mediante carteles o edictos, antecedente de la Gaceta de Madrid y el Boletín Oficial ${ }^{50}$. Todavía se le ocurrió al licenciado Tapia una forma suplementaria de divulgación de su auto, y fue su inserción al comienzo de obras impresas por entonces, antes incluso de sus preliminares, caso de la Vida del escudero Marcos de Obregón. Decisión gracias a la que tenemos noticia accesible de la culminación del proceso en que se integraba el auto del Consejo ${ }^{51}$. Es de creer que el deseo del comisionado fue insertar este aviso en un número amplio de obras, para asegurar su divulgación. O, por lo menos, en obras de las que cabía esperar amplia difusión, por su adecuación para el entretenimiento -caso del mentado Marcos de Obregón- o para el continuo uso del público letrado, como el Quaderno de las leyes añadidas a la Nueva Recopilación de las leyes destos reynos 52 .

Con todo, si la actitud de los impresores hacia la transcripción completa del conjunto de los preliminares obligada por la legislación era de reticencia en el caso de las obras propias (lo que se manifestó en la paulatina y creciente aparición de sumas de la licencia y del privilegio, o la supresión de la primera cuando eran concedidos ambos), esta actitud debió ser más rotunda en lo que no dejaba de ser una cesión gratuita de espacio en sus obras para un anuncio oficial. Por ello, de la breve búsqueda que he hecho cabe deducir que no fueron muchas las obras que incluyeron la transcripción del señalado auto y que el comisionado debió valerse de los impresores con los que tenía relación, como Juan de la Cuesta. Pero, incluso en

${ }^{50}$ Lorenzo CADARSO, P. L. (2006). "El documento real en el siglo XVII. Algunas novedades diplomáticas", en Juan Carlos GALENDE DíAZ, dir., V Jornadas Científicas sobre documentación de Castilla e Indias en el siglo XVII, Madrid: Departamento de Ciencias y Técnicas Historiográficas, Universidad Complutense de Madrid, pp. 225-238, pp. 232-233 [recurso electrónico] <www.ucm.es/ centros/cont/descargas/documento11379.pdf> [Consultado: 8-2011].

${ }^{51}$ Transcrito de otra obra por REYES GómEZ, F. DE LOS (2000). El libro en España y América..., II, pp. 841-842.

52 En este caso, y de acuerdo con el tiempo transcurrido desde la publicación del instrumento legal, fue inserto no al principio de los preliminares, si no al final, Quaderno de las leyes añadidas a la Nueva Recopilación de las leyes destos reynos... Año 1620... En Madrid por Francisco Abarca de Angulo.... Es importante destacar que lo que se insertó en estas obras no fue el auto del Consejo propiamente dicho, sino el suscrito por el licenciado Pedro de Tapia, que refiere indirectamente el del Consejo, al ordenar su fijación en parte visible de las librerías de la Corte. 
este caso, la comprensión tenía un límite ${ }^{53}$. Lo más curioso del caso es que, hasta donde sé, el auto apenas debió ser incluido en el sector de obras a las que se dirigía, aquellas de autores castellanos impresas en el extranjero ${ }^{54}$. El auto de Tapia continuó insertándose en obras impresas bastantes años después de su emisión, como la Historia oriental de las peregrinaciones de Fernán Méndez Pinto, publicada en $1628^{55}$. Pero, al margen de los detalles, en este caso se advierte que, por debajo del auto emitido por el Consejo, todavía podía haber una suerte de

${ }^{53}$ Así, en Muerte de Dios por vida del hombre deduzida de las postrimerías de Christo Señor nuestro. Primera parte... por el padre F. Hernando de Camargo..., En Madrid, por Juan de la Cuesta, año 1619 [recurso electrónico] Biblioteca Digital Hispanica. Biblioteca Nacional de España < http://bibliotecadigitalhispanica.bne.es/view/action/singleViewer.do?dvs=1346932881687 258\&local e=es\&VIEWER_URL=/view/action/singleViewer.do?\&DELIVERY_RULE_ID=10\&frameId=1\&use Pid1=true\&usePid2=true > [Consultado 09-2011], no se incluyó ya el auto completo, sino una breve Advertencia, antes de las aprobaciones: "Por la ley 24 del título séptimo del libro primero de la Nueva Recopilación está prohibido, y mandado, que ningún libro de romance, impresso fuera destos reynos, se pueda meter, ni vender, so graves penas, aunque sean impressos en la Corona de Aragón, Valencia, Cataluña y Navarra. Y ahora de nuevo está mandado guardar por un auto de los señores del Real Consejo a 9 días de octubre 1617”. La remisión correspondía al lugar en que había sido incluida la Pragmática de 1558 en la Nueva Recopilación. En línea con lo dicho, también la Primera y segunda parte del estilo y método de escribir cartas.../ compuesto por Iuan Vicente Peligero..., En Madrid, por Iuan de la Cuesta, 1619, aludía a la indicada ley de recopilación, tras la licencia de impresión y antes de la aprobación, pero por razones de espacio se omitió la alusión al auto, curiosamente, el motivo original de inserción del aviso en obras impresas.

${ }^{54}$ Por ejemplo, no constaba ni en La discreta Galatea de Miguel de Cervantes Saavedra..., Em Lisboa, por Antonio Álvarez. Año 1618, [recurso electrónico] Biblioteca Digital Hispanica. Biblioteca Nacional de España <http://bibliotecadigitalhispanica.bne.es/view/action/single Viewer. do?dvs=1346932222370 326\&locale=es\&VIEWER_URL=/view/action/singleViewer.do?\&DELIVE RY_RULE_ID=10\&frameId=1\&usePid1=true\&usePid2=true> [Consultado 09-2011] ni en Los trabajos de Persiles y Sigismunda, historia setentrional, por Miguel de Cervantes Saavedra... En Bruselas, por Humberto Antonio,..., año 1618 [recurso electrónico] Biblioteca Digital Hispanica. Biblioteca Nacional de España <http://bibliotecadigitalhispanica.bne.es/view/action/singleViewer. do?dvs=1346932441449 646\&locale=es\&VIEWER_URL=/view/action/singleViewer.do?\&DELIVE RY_RULE_ID=10\&frameId=1\&usePid1=true\&usePid2=true > [Consultado 09-2011]. Una excepción la constituyen los Refranes o proverbios en romance que coligió, y glossó el el comendador Hernán Núñez, professor de retórica y griego en la Universidad de Salamanca... Año 1621. Con licencia. En Lérida..., que incluyó la parte dispositiva del auto de Tapia, directamente tras el encabezamiento [recurso electrónico] Google Books <http://books.google.es/books?id=zhJTveLHp8cC\&printsec= frontcover\&dq=refranes+o+proverbios+en+romance\&source=bl\&ots=1ZX6giTWnW\&sig=SBH4FKtV912mEJn kkTxmdeJf0\&hl=en\&sa=X\&ei=bo9IUMGnMcy7hAfb9oHACQ\&ved=0CDAQ6AE wAA\# $\mathrm{v}=$ onepage $\& \mathrm{q}=$ refranes $\% 20 \mathrm{o} \% 20$ proverbios $\% 20 \mathrm{en} \% 20$ romance $\& \mathrm{f}=$ false $>$ [Consultado 08 2012].

${ }^{55}$ Versión a partir de la que ReYes GómeZ, F. DE Los (2000). El libro en España y América..., op. cit., II, pp. 841-842, lo reproduce en su apéndice documental. Este autor, en op. cit., I, p. 283 menciona otras obras y fuentes de orden legislativo en las que el auto fue incluido por entonces.. 
escalón inferior en la cadena legislativa, un auto formulado por uno de sus miembros, y en los mismos términos que los emitidos por el organismo. Que, además, mencionaba un tercero, promulgado por el propio oidor con la misma fecha, que establecía la obligatoriedad del registro de las obras importadas en el Consejo, para reducir el riesgo de inobservancia del conjunto de estas disposiciones. De ambos autos, el extenso del Consejo y el intenso del oidor, se deducía por lo demás un contorno muy definido para los conceptos de naturaleza y extranjería, y los contrapuestos efectos jurídicos que, en su caso, podían surtir.

La indicada no sería la última vez en la que un auto fue utilizado para concretar disposiciones más genéricas, hasta el punto de acotar las condiciones concretas en que determinada obra llegaba al público. Una vez editado por Alonso López de Haro su famoso Nobiliario ${ }^{56}$, en la Corte surgió el temor de que fuese invocado como autoridad por pretendientes de hidalguía, hábitos militares y otros privilegios propios de la condición nobiliaria, de manera que se acordó lo que hoy se denominaría secuestro de la edición, y se confirió al licenciado don Diego de Corral y Arellano, ya como oidor, el examen y valoración de la obra. Tres años después recibió el Consejo orden real que ordenaba la devolución de la obra al autor y su libre venta, con la condición de insertar auto adjunto, con cláusula de exclusión de efectos jurídicos, que invalidaba la obra como título válido para reclamar derechos ${ }^{57}$. El auto es de destacar por varios motivos. En primer lugar corroboraba la flexibilidad de esta forma jurídica, su capacidad de adaptación a supuestos inicialmente no contenidos en la legislación específica de un ramo, revelados por su puesta en práctica. En segundo lugar, contrastaba de forma estridente con un aspecto que ya he subrayado, la libertad de iniciativa de que gozaba el Consejo en el proceso de formulación de los autos y acuerdos, correspondiente a su identificación con la persona real y la inserción en su espacio reservado. Puesto que se remitió al Consejo el auto ya redactado, a falta sólo de la correspondiente rúbrica de sus miembros. Y este contraste era más significativo por cuanto se consumaba en una época en que el despliegue de la política del Conde Duque estaba afectando visiblemente a la posición institucional del organismo, como demostró la perdida del conocimiento de las competencias entre los Consejos cortesanos por parte de su Sala de Gobierno, en beneficio de junta específica ${ }^{58}$.

${ }^{56}$ Nobiliario genealógico de los reyes y títulos de España... compuesto por Alonso López de Haro... En Madrid: Por Luis Sánchez, 1622; Segunda parte del nobiliario genealogico de los reyes y titulos de España..., En Madrid, por la viuda de Fernando Correa de Montenegro, 1622.

${ }^{57}$ Autos y acuerdos del Consejo de que se halla memoria en los libros, ..., op. cit., auto 231.

58 Por Cédula Real de 9 de diciembre de 1625, Juan de Moriana, Discursos generales y particulares de el gobierno general y político de el Conssejo Real y Supremo de justicia de estos 
Quizá el disgusto del Consejo con la situación explique que en este caso, de forma excepcional en el conjunto de los autos publicados en la edición impresa de $1618^{59}$, procediese a anotarse puntillosamanete toda la sucesión de comunicaciones administrativas que habían desembocado en la orden real: la certificación de Lázaro de Ríos Angulo, escribano de Cámara del Consejo, sobre la licencia y posterior recogida de la obra, el decreto real que estipulaba poner "en cada cuerpo al principio dél el auto cuya copia va aquí, aviéndole primero señalado los del Consejo..." y, finalmente el auto propiamente dicho, de 24 de octubre de 1625, con cláusula que certificaba el origen externo del mismo y redacción que, de puertas afuera, salvaba la posición del Consejo: "Y visto el dicho decreto por los señores del Consejo se proveyó el auto del tenor siguiente...". Tan detallada descripción del proceso era buena prueba, por lo demás, del carácter restringido de las primeras compilaciones de autos, y parecía dar la razón al valido cuando, en su Gran Memorial de 1624 afirmaba que el Consejo tendía a mostrar su primacía incluso ante la propia fuente de la misma, la Majestad Real. Aconsejaba garantizar su autoridad e independencia, pero añadía: “... y como esta es delegada de V. Majd. escusar de decir a V. Majd. que siempre conviene no dejarles olvidar desta verdad, porque la mano que hoy tiene es tan grande que a no conservarles en el reconocimiento que he apuntado podría llegar a ser de inconvenientes invencibles..." ${ }^{, 60}$.

Entretanto, el auto de 15 de septiembre de 1617 no había terminado con la entrada fraudulenta en Castilla de obras impresas en el extranjero, que con los años fue a más. Mediado el siglo XVII, el gremio de impresores de Madrid denunció a los libreros de la Corte por mandar imprimir obras de naturales castellanos en Lyon y otras ciudades. Tras un largo pleito, el Consejo dio la razón a los denunciantes invocando la Pragmática de 1610 y el referido Auto de 1617. Y lo hizo, nuevamente, mediante Auto de 2 de octubre de 1655, ratificatorio de las referidas disposiciones, confirmado por otro de 9 de abril de $1658^{61}$.

reynos de Castilla y León..., en Dios, S. DE (1986). Fuentes para el estudio del Consejo Real..., pp. 291-292.

59 O más correctamente en el cuaderno añadido a la misma en 1634, cuestión sobre la que no puedo extenderme aquí.

${ }^{60}$ Elliott, J. H.-Peña, J. F. De La (1978). Memoriales y cartas del Conde Duque de Olivares, I, Política interior: 1621 a 1627, Madrid: Ediciones Alfaguara, p. 79.

${ }^{61}$ Sobre este pleito, Moll, J. (1988). «De impresores y libreros: un pleito de 1651», en Varia Bibliographica. Homenaje a José Simón Díaz, Kassel: Edition Reichenberger, pp. 483-490, así como Reyes Gómez, F. De Los (2000). El libro en España y América..., op. cit., I, pp. 285-288, y las fuentes allí citadas. 


\section{CONCLUSIÓN.}

En definitiva, la intervención del Consejo Real en los referidos campos evidenciaba su permanente capacidad normativa en el espacio cortesano, en el que ejercía una función transmisora de las decisiones reales desde el ámbito del monarca hacia el conjunto de los reinos. A su vez, la continua transformación de las circunstancias en las que se desarrollaba la actividad de estos ramos hacía evidente la vitalidad orgánica de aquellas materias que conformaban la realidad cortesana. Su ritmo era mucho más intenso que la capacidad de la autoridad regia para controlarlas. No obstante, los autos y acuerdos fueron un voluntarioso intento de encauzar esa vitalidad conforme a los intereses de la Monarquía, dotados como estaban de un carácter urgente y correctivo idóneo para articular prioridades políticas como, por ejemplo, el desarrollo de control ideológico propio de la Pragmática sobre impresión de libros de 1558. Pero, pese a su evidente aplicación, los autos y acuerdos denotaban un carácter de enunciación ideal siempre vulnerable a la inercia de la realidad. 
